\title{
PENGARUH KEPEMIMPINAN TRANSFORMASIONAL, MOTIVASI DAN KEPUASAN KERJA TERHADAP KOMITMEN ORGANISASIONAL
}

\author{
Desak Made Lingga Suadnyani ${ }^{1}$ \\ I Gusti Salit Ketut Netra ${ }^{2}$ \\ ${ }^{1,2}$ Fakultas Ekonomi dan Bisnis Universitas Udayana (Unud), Bali, Indonesia \\ email : desaksuadnyani@gmail.com
}

\begin{abstract}
ABSTRAK
Tujuan penelitian ini adalah untuk menganalisis pengaruh kepemimpinan transformasional, motivasi dan kepuasan kerja terhadap komitmen organisasional di Wyndham Garden Hotels Kelurahan/Desa Kuta Kabupaten Badung. Jenis data yang diguanakan dalam penelitian ini adalah data kuantitatif dan kualitatif. Data yang digunakan dalam penelitian ini adalah data primer yang diperoleh langsung dari sumbernya yaitu berupa kuesioner yang didapatkan langsung melalui pengisian kuesioner oleh responden yaitu karyawan Wyndham Garden Hotels Kelurahan/Desa Kuta Kabupaten Badung. Populasi dalam penelitian ini adalah seluruh karyawan di Wyndham Garden Hotels Kelurahan/Desa Kuta Kabupaten Badung yang berjumlah 108 orang. Dari hasil pengujian didapatkan bahwa kepemimpinan transformasional berpengaruh positif signifikan terhadap komitmen organisasional di Wyndham Garden Hotels Kelurahan/Desa Kuta Kabupaten Badung. Motivasi berpengaruh positif signifikan terhadap komitmen organisasional di Wyndham Garden Hotels Kelurahan/Desa Kuta Kabupaten Badung. Kepuasan kerja berpengaruh positif signifikan terhadap komitmen organisasional di Wyndham Garden Hotels Kelurahan/Desa Kuta Kabupaten Badung.
\end{abstract}

Kata Kunci: kepemimpinan transformasional, motivasi, kepuasan kerja dan komitmen organisasional.

\begin{abstract}
The purpose of this study was to analyze the effect of transformational leadership, motivation and job satisfaction on organizational commitment at Wyndham Garden Hotels Kuta Village Badung Regency. Data type has been used in this study that are quantitative and qualitative. Data has been used in this study are primary that get directly through fill of questioner by respondents. Population in this study is all employee in Wyndham Garden Hotels Kuta Village Badung Regency by number of 108 people. From the result shows that transformational leadership have been positive and significant toward organizational commitment at Wyndham Garden Hotels Kuta Village Badung Regency. Motivation have been positive and significant toward organizational commitment at Wyndham Garden Hotels Kuta Village Badung Regency. Job satisfaction have been positive and significant toward organizational commitment at Wyndham Garden Hotels Kuta Village Badung Regency.
\end{abstract}

Keywords: transformational leadership, motivation, job satisfaction and organizational commitment. 
Desak Made Lingga Suadnyani, Pengaruh Kepemimpinan Transformasional...

\section{PENDAHULUAN}

Salah satu bagian penting dalam sebuah organisasi adalah sumber daya manusia. Suatu organisasi dikatakan berhasil atau tidak mencapai tujuan ditentukan oleh seberapa besar komitmen organisasional karyawan terhadap organisasi. Menurut Taurisa dan Ratnawati (2012), sebuah komitmen organisasional tidak hanya sebatas kepasifan dalam hal loyalitas melainkan juga berkaitan dengan keaktifan dan tekad karyawan untuk berkontribusi kepada organisasi. Komitmen dari karyawan sangatlah penting bagi organisasi agar kegiatan organisasi dapat berjalan secara efektif dan efisien (Kumar dan Yacob, 2012). Sumber daya manusia yang unggul dan mampu bersaing, membutuhkan peran pemimpin yang dapat mempengaruhi seluruh karyawan untuk meningkatkan kualitas diri. Salah satu jenis kepemimpinan yang dapat diterapkan oleh seorang pemimpin adalah kepemimpinan transformasional. Gaya kepemimpinan tersebut memiliki kelebihan yaitu dengan gaya kepemimpinan tersebut akan meningkatkan loyalitas karyawan dan tingkat peduli karyawan kepada atasannya semakin meningkat sehingga menyebabkan motivasi bawahan akan semakin meningkar dari yang diharapkan (Alam dkk., 2013). Kepemimpinan transformasional pada dasarnya dapat menciptakan lingkungan yang memotivasi karyawan dalam mencapai tujuan organisasi serta mengembangkan minat dalam bekerja (Kresnandito dan Fajrianthi, 2012). Dalam penelitian Jain dan Taranjeet (2016) menyatakan bahwa kepemimpinan transformasional berpengaruh positif terhadap komitmen organisasional karyawan. Selain kepemimpinan transformasional, motivasi juga mempengaruhi 
komitmen organisasional karyawan. Motivasi merupakan proses yang menjelaskan mengenai kekuatan, arah dan ketekunan seseorang dalam upaya untuk mencapai tujuan (Robbins, 2015:127). Ek dan Elegwa (2013) menyatakan bahwa motivasi kerja dapat menjadi pendorong yang ada dalam diri manusia dan dapat mengarahkan perilakunya untuk melaksanakan tugas dan tanggung jawabnya. Widyaningrum (2011) menyatakan bahwa motivasi memiliki pengaruh positif terhadap komitmen organisasional karyawan. Shaheen dan Farooqi (2014) menyatakan bahwa motivasi kerja berpengaruh positif terhadap komitmen organisasional karyawan. Selain kepemimpinan transformasional dan motivasi, kepuasan kerja juga mempengaruhi komitmen organisasional. Kepuasan kerja merupakan sesuatu yang bersifat individual dan setiap individu memiliki tingkat kepuasan yang berbeda sesuai dengan sistem nilai yang berlaku pada dirinya (Rivai dan Sagala, 2011:856). Imam et al. (2014) menyatakan bahwa kepuasan kerja berpengaruh positif dan signifikan terhadap komitmen organisasional. Penelitian ini dilaksanakan di Wyndham Garden Hotels yang berlokasi di Jalan Pantai Kuta No. 99x, Kelurahan/Desa Kuta Kabupaten Badung. Masalah mengenai komitmen organisasional karyawan dapat dilihat dari kurangnya loyalitas karyawan terhadap perusahaan untuk tetap tinggal di dalam perusahaan. Loyalitas karyawan tercermin melalui ketersediaan dan kemauan pegawai untuk berkontribusi terhadap organisasi dan adanya keinginan untuk tidak keluar dari organisasi (Priansa, 2014:234). Permasalahan yang terkait dengan kepemimpinan transformasional yang menyebabkan komitmen organisasional karyawan menurun bahwa keengganan pimpinan untuk mengembangkan keahlian karyawannya yang 
Desak Made Lingga Suadnyani, Pengaruh Kepemimpinan Transformasional...

berdampak pada kurangnya keterlibatan karyawan dalam menyalurkan ide idenya yang sekiranya dapat dipertimbangan oleh pimpinan saat mengambil keputusan selain itu kurangnya dorongan dari pemimpin untuk karyawan dalam mengerjakan tugas - tugasnya, sehingga hal tersebut menyebabkan karyawan belum mampu menyelesaikan tugasnya secara maksimal. Permasalahan terkait motivasi dalam perusahaan diketahui bahwa manajemen kurang memberikan penghargaan kepada karyawan yang bekerja dalam perusahaan. Kurangnya pemberian penghargaan kepada karyawan menjadi penyebab menurunnya motivasi kerja karyawan dalam mengerjakan tugas-tugasnya. Hasibuan (2012:92) menyatakan bahwa motivasi akan memberikan inspirasi, dorongan, semangat kerja bagi karyawan sehingga terjalin hubungan kerja yang baik antara karyawan dan pimpinan sehingga tujuan organisasi dapat tercapai secara maksimal. Terkait dengan masalah kepuasan kerja didalam perusahaan yang menyebabkan menurunnya komitmen organisasional karyawan dapat dilihat dari karyawan tidak semangat dalam mengerjakan pekerjaannya serta kurangnya kesempatan karyawan untuk mendapatkan jabatan yang lebih tinggi. Hal tersebut dapat menjadi indikasi permasalahan mengenai kepuasan kerja karyawan yang akan berdampak terhadap rendahnya komitmen organisasional karyawan.

Rumusan masalah dalam penelitian ini adalah 1) Apakah kepemimpinan transformasional berpengaruh positif dan signifikan terhadap komitmen organisasional di Wyndham Garden Hotels Kelurahan/Desa Kuta Kabupaten Badung?, 2) Apakah motivasi berpengaruh positif dan signifikan terhadap komitmen organisasional di Wyndham Garden Hotels Kelurahan/Desa Kuta 
Kabupaten Badung?, 3) Apakah kepuasan kerja berpengaruh positif dan signifikan terhadap komitmen organisasional di Wyndham Garden Hotels Kelurahan/Desa Kuta Kabupaten Badung?

Tujuan dari penelitian ini adalah 1) untuk menganalisis pengaruh kepemimpinan transformasional terhadap komitmen organisasional di Wyndham Garden Hotels Kelurahan/Desa Kuta Kabupaten Badung, 2) untuk menganalisis pengaruh motivasi terhadap komitmen organisasional di Wyndham Garden Hotels Kelurahan/Desa Kuta Kabupaten Badung, 3) untuk menganalisis pengaruh kepuasan kerja terhadap komitmen organisasional di Wyndham Garden Hotels Kelurahan/Desa Kuta Kabupaten Badung.

Manfaat dari penelitian ini diharapkan dapat memperluas pengetahuan bagi pembaca mengenai pengaruh motivasi, kepemimpinan transformasional dan kepuasan kerja terhadap komitmen organisasional yang diperkuat dengan bukti empirik yang diperoleh oleh penulis. Penelitian ini juga diharapkan dapat memberikan manfaat bagi pihak internal perusahaan untuk dominan menggunakan kepemimpinan transformasional dalam membina karyawan, membangun motivasi dan menciptakan kepuasan kerja bagi karyawan yang nantinya akan meningkatkan komitmen organisasional di Wyndham Garden Hotels Kelurahan/Desa Kuta Kabupaten Badung.

Komitmen organisasional adalah suatu keadaan sejauh mana seorang pekerja mengenali organisasi dan memiliki keinginan untuk melanjutkan karirnya dalam organisasi tersebut (Rehman et al., 2013). Karyawan yang memiliki ikatan yang kuat dengan organisai mereka dapat dipercayai bahwa mereka adalah 
Desak Made Lingga Suadnyani, Pengaruh Kepemimpinan Transformasional...

individu yang kurang diharapkan untuk meninggalkan organisasi mereka (Altinoz et al., 2012). Robbins dan Judge (2008) menyatakan bahwa komitmen organisasi (organizational commitment) merupakan suatu keadaan dimana seorang karyawan memihak terhadap tujuan tujuan organisasi serta memiliki keinginan untuk mempertahankan keanggotaannya dalam organisasi tersebut. Mohamed dan Anisa (2012) menyatakan bahwa komitmen operasional mengarah pada kesiapan seorang karyawan dalam merealisasikan standar, tujuan, prinsip, nilai - nilai dan etika organisasi untuk bertahan dalam organisasi baik pada situasi dan kondisi apapun.

Priansa (2014:234) menyatakan bahwa lima prinsip yang harus diterapkan oleh pemimpin untuk membangkitkan komitmen organisasional adalah memberikan tanggapan dengan empati, meminta bantuan dan mendorong keterlibatan, memelihara atau meningkatkan harga diri, mengungkapkan pikiran, perasaan dan rasional dan memberikan dukungan tanpa mengambil alih tanggung jawab. Menurut Priansa (2014:237) salah satu cara yang dapat dilakukan gunna membangkitkan komitmen organisasional pada karyawan adalah make it charismatic, build the traditional, have comprehensive grievance procedures, provide extensive two-way communication, create a sense of community, build value-based homogeneity, share and share a like, emphasize barn rising, crossutilization and team work, get together, support employee development, commit to actualizing, provide first year challenge, enrich and empower, promote from within, provide develompmental activities, the question of employee security, commit to people first value, put it in writing, hire right kind managers, walk the 
talk. Menurut Sopiah (2008) dampak komitmen organisasional dapat ditinjau dari dua sudut. Berdasarkan aspek organisasi, rendahnya tingkat komitmen seorang karyaawan dapat berpengaruh terhadap turnover, tingginya absensi, meningkatnya kelambanan kerja dan kurang intensitas untuk bertahan sebagai karyawan di organisasi tersebut, rendahnya kualitas kerja dan kurangnya loyalitas pada organisasi. Ditinjau dari sudut karyawan, komitmen karyawan yang tinggi akan berdampak pada peningkatan karir karyawan tersebut. Faktor - faktor yang mempengaruhi komitmen organisasional menurut McShane dan Glinow (2000) dalam Priansa (2014) adalah sebagai berikut: keadilan dan kepuasan kerja, keamanan kerja, pemahaman organisasi, keterlibatan pegawai dan kepercayaan pegawai.

Setiap organisasi membutuhkan pemimpin yang dapat meningkatkan komitmen organisasional karyawannya (Saeed, 2015). Salah satu faktor penting yang mempengaruhi komitmen karyawan adalah perilaku yang diperlihatkan melalui kepemimpinan transformasional (Jain dan Duggal, 2015). Pendekatan transformasional merupakan pendekatan baru yang sangat banyak diteliti dan menjadi popular saat ini (Northouse, 2013:175). Surbakti (2013) menjelaskan bahwa besar kecilnya perubahan yang dilakukan oleh karyawan yang dipengaruhi oleh pemimpinnya merupakan salah satu bukti adanya interaksi antara pimpinan dengan bawahannya dalam pendekatan transformasional. Hughes et al. (2012:542) mengemukakan kepemimpinan transformasional adalah perilaku pemimpin yang memiliki visi, keahlian retrorika dan pengelolaan kesan yang baik yang digunakan untuk menguatkan ikatan emosional pemimpin dengan 
Desak Made Lingga Suadnyani, Pengaruh Kepemimpinan Transformasional...

bawahannya sehingga menimbulkan adanya emosi bawahan dan kesediannya untuk bekerja sesuai dengan visi pemimpinnya. Pemimpin transformasional berupaya melakukan transforming of visionary menjadi visi bersama sehingga mereka (bawahan dan pimpinan) bekerja untuk mewujudkan visi menjadi kenyataan (Adinata, 2015). Penerapan kepemimpinan transformasional akan menyebabkan bawahan memiliki rasa percaya diri, loyalitas, respek pada pimpinannya, meningkatkan kepercayaan dan dihargai sehingga dapat meningkatkan motivasi bawahan untuk bertindak lebih dari yang diharapkan (Simanjuntak dan Calam, 2012).

Abu et al. (2009) menyatakan pedoman yang dapat digunakan untuk mewujudkan faktor pengaruh individu dalam memecahkan masalah serta peningkatan pada diri karyawan mengenai gaya transformasional adalah memberdayakan seluruh kekuatan sumber daya organisasi, membuta sebuah trobosan baru dan inovatif baik dalam kelompok maupun organisasi serta memberikan kolega-subordinate dalam meningkatkan kesadaran karyawan terhadap peranannya dalam sebuah organisasi.

Agusthina et al. (2012) menyatakan bahwa motivasi adalah keinginan yang terdapat pada seseorang individu yang merangsang untuk melakukan tindakantindakan. Terry dan Leslie (2009:168) menyatakan bahwa motivasi menyangkut perilaku manusia dan merupakan sebuah unsur yang vital dalam manajemen dan motivasi dapat didefinisikan sebagai membuat seseorang menyelesikan pekerjaan dengan semangat, karena orang itu ingin melakukannya. Manullang dan Manullang (2008:164) menyatakan bahwa daya dorong yang ada dalam diri 
seseorang, sering disebut motif. Manullang dan Manullang (2008:166) menyatakan bahwa motivasi kerja adalah pendorong semangat kerja. Pemberian dorongan berupa motivasi dari atasan kepada bawahan yang dilakukan secara terus menerus akan menciptakan hubungan yang baik antara atasan dengan bawahan (Purnama, 2016). Motivasi mempersoalkan bagaimana cara menggerakkan daya dan potensi bawahannya, agar mau bekerja sama secara produktif, berhasil mencapai dan mewujudkan tujuan yang telah ditetapkan, maka dari itu motivasi sangat penting karena motivasi merupakan hal yang menyebabkan, menyalurkan, dan mendukung perilaku manusia (Sumanto dan Herminingsih, 2016).

Menurut Priansa (2014:204) sumber motivasi dapat digolongkan menjadi dua sumber. Pertama, motivasi intrinsik. Faktor individual yang mendorong karyawan untuk melakukan sesuatu adalah minat, sikap positif dan kebutuhan. Kedua, motivasi ekstrinsik. Faktor utama yang mempengaruhi motivasi ekstrinsik karyawan dalam sebuah organisasi ada dua yaitu kesempatan kerja dan motivator. Hasibuan (2012:150) menyatakan bahwa jenis-jenis motivasi adalah motivasi positif dan motivasi negatif. Motivasi positif maksudnya manajer memotivasi (merangsang) bawahan dengan memberikan hadiah kepada mereka yang berprestasi di atas prestasi standar. Motivasi negatif maksudnya manajer memotivasi bawahan dengan standar mereka akan mendapat hukuman.

Menurut Hasibuan (2012:146) pemberian motivasi pada karyawan dilakukan untuk beberapa tujuan yaitu tingkat kepuasan kerja dan moral karyawan meningkat, tingkat disiplin karyawan dapat meningkat, meningkatnya 
Desak Made Lingga Suadnyani, Pengaruh Kepemimpinan Transformasional...

produktivitas karyawan dalam bekerja, menjaga kestabilan kerja karyawannya, keefektifan pengadaan karyawan dapat meningkatkan, membuat hubungan kerja yang baik, tingkat loyalitas karyawan meningkat, kesejahteraan karyawan meningkat, meningkatkan partisipasi dan kreatifitas karyawan, karyawan memiliki rasa tanggung jawab yang tinggi terhadap seluruh tugasnya dan tingkat efisiensi penggunaan bahan baku dan peralatan dapat meningkat.

Zainal dkk. (2014:2460) menyatakan bahwa kepuasan kerja adalah penilaian dari pekerja tentang seberapa jauh pekerjaannya secara keseluruhan memuaskan kebutuhannya. Setiap individu pekerja memiliki karakteristik yang berbeda beda, maka tingkat kepuasan kerjanya pun berbeda - beda, dimana tinggi rendahnya kepuasan kerja tersebut dapat memberikan dampak yang tidak sama (Priansa, 2016). Kepuasan kerja merupakan sebuah sikap karyawan secara emosional yang menyenangkan dan mencintai pekerjaannya dengan sepenuh hati (Han dkk., 2012). Robbins (2015:46) menyatakan bahwa kepuasan kerja (job satisfaction) adalah suatu perasaan positif tentang pekerjaan yang dihasilkan dari suatu evaluasi pada karakteristik - karakteristiknya. Salleh et al. (2012) menyatakan bahwa kepuasan kerja dibagi menjadi 2 kata yaitu kepuasan dan kerja. Kepuasan dengan ketidakpuasan karyawan merupakan perbandingan antara apa yang diterima dengan apa yang diharapkan, diinginkan atau dipikirkan oleh seseorang (Teguh dan Rosidah, 2009:236).

Robbins (1996:184) mengemukakan beberapa respon yang dilakukan karyawan yang merasa tidak puas terhadap pekerjaannya, diantaranya adalah: exit (keluar), voice (suara), loyality (kesetiaan), dan neglect (pengabaian). Menurut 
Aydogdu dan Asikgil (2011) konsekuensi ketidakpuasan kerja karyawan ditunjukkan dengan: absensi, keinginan keluar, produktivitas rendah, pensiun dini, Komitmen organisasi rendah, kesehatan mental dan fisik, dan kepuasan hidup. Sutrisno (2014:80) mengemukakan faktor-faktor yang mempengaruhi kepuasan kerja adalah faktor psikologis yang meliputi minat, ketentraman dalam kerja, sikap terhadap kerja, bakat dan keterampilan. Faktor sosial merupakan faktor yang berhubungan dengan interaksi sosial antarkaryawan maupun karyawan dengan atasan. Faktor fisik meliputi jenis pekerjaanm pengaturan waktu dari waktu istirahat, perlengkapan kerja, keadaan ruangan, suhu, penerangan, pertukaran udara, kondisi kesehatan karyawan dan umur. Faktor finansial meliputi sistem dari besarnya gaji, jaminan sosial, macam-macam tunjangan, fasilitas yang diberikan dan promosi.

Kepemimpinan transformasional meliputi pengembangan hubungan yang lebih dekat antara pemimpin dengan bawahannya, bukan hanya sekedar sebuah perjanjian tetapi lebih didasarkan kepada kepercayaan dan komitmen (Simanjuntak dan Calam, 2012). Bushra et al. (2011) menyatakan bahwa terdapat pengaruh yang positif antara kepemimpinan transformasional terhadap kepuasan kerja dan komitmen organisasional. Njoroge et al. (2015) menyatakan bahwa terdapat pengaruh signifikan antara kepemimpinan transformasional terhadap komitmen organisasional. Supit (2016) menyatakan bahwa kepemimpinan transformasional berpengaruh signifikan terhadap komitmen organisasional karyawan. Jain dan Taranjeet (2016) juga menemukan bahwa kepemimpinan transformasional berpengaruh positif terhadap komitmen organisasional 
Desak Made Lingga Suadnyani, Pengaruh Kepemimpinan Transformasional...

karyawan. Berdasarkan penjelasan diatas, maka dapat disusun hipotesis sebagai berikut:

$\mathrm{H}_{1}$ : kepemimpinan transformasional berpengaruh positif dan signifikan terhadap komitmen organisasional di Wyndham Garden Hotels Kelurahan/Desa Kuta Kabupaten Badung.

Suatu perusahaan membutuhkan pemberian motivasi kepada karyawan yang berguna untuk mendorong karyawan agar dapat mewujudkan tujuan perusahaan itu sendiri (Wardhani dkk., 2015). Awolusi (2013) menyatakan bahwa motivasi berpengaruh positif terhadap komitmen karyawan. Wardhani dkk. (2015) menyatakan bahwa motivasi berpengaruh secara signifikan terhadap komitmen organisasional. Sharma et al. (2016) menyatakan bahwa terdapat pengaruh yang signifikan antara motivasi terhadap komitmen karyawan. Salleh et al. (2016) menyatakan bahwa ada pengaruh positif antara motivasi kerja dan komitmen organisasional karyawan. Putri dkk. (2015) menyatakan bahwa motivasi kerja berpengaruh signifikan terhadap komitmen organisasional karyawan. Berdasarkan penjelasan diatas, maka dapat disusun hipotesis sebagai berikut:

$\mathrm{H}_{2}$ : motivasi berpengaruh positif dan signifikan terhadap komitmen organisasional di Wyndham Garden Hotels Kelurahan/Desa Kuta Kabupaten Badung.

Kepuasan kerja merupakan hal penting yang dimiliki individu di dalam bekerja, dimana setiap individu pekerja memiliki karakteristik yang berbeda beda, maka tingkat kepuasan kerjanya pun berbeda - beda pula (Priansa, 2014). Shah (2014) menyatakan bahwa terdapat pengaruh positif antara kepuasan kerja 
terhadap komitmen organisasional karyawan. Imam et al. (2014) menyatakan bahwa terdapat pengaruh positif antara kepuasan kerja terhadap komitmen organisasional karyawan. Wardhani dkk. (2015) menyatakan bahwa kepuasan kerja berpengaruh signifikan terhadap komitmen organisasional karyawan. Tentama dan Pranungsari (2016) menyatakan bahwa terdapat pengaruh positif antara kepuasan kerja guru terhadap komitmen organisasional. Berdasarkan penjelasan diatas, maka hipotesis yang dapat disusun sebagai berikut:

$\mathrm{H}_{3}$ : kepuasan kerja berpengaruh positif dan signifikan terhadap komitmen organisasional di Wyndham Garden Hotels Kelurahan/Desa Kuta Kabupaten Badung.

\section{METODE PENELITIAN}

Berdasarkan pemaparan sebelumnya, maka pendekatakan kuantitatif digunakan dalam penelitian ini dengan penelitian yang bersifat asosiatif (hubungan). Penelitian ini berlokasi di Wyndham Garden Hotels yang beralamat di Jalan Pantai Kuta No. 99x, Kelurahan/Desa Kuta Kabupaten Badung. Objek penelitian adalah kepemimpinan transformasional, motivasi, kepuasan kerja dan komitmen organisasional. Variabel bebas dalam penelitian ini adalah variabel kepemimpinan transformasional, motivasi dan kepuasan kerja yang disimbolkan dengan $\mathrm{X}_{1}, \mathrm{X}_{2}$, dan $\mathrm{X}_{3}$. Variabel terikat yaitu komitmen organisasional yang disimbolkan dengan Y.

Meyer dan Allen (1991) menyatakan bahwa komitmen organisasional (Y) adalah keadaan psikologis yang menunjukan ciri hubungan karyawan dengan 
Desak Made Lingga Suadnyani, Pengaruh Kepemimpinan Transformasional...

organisasi dan memiliki implikasi pada keputusan untuk melanjutkan atau menghentikan keanggotaannya di dalam organisasi. Menurut Meyer dan Allen (1991) adapun indikator dari komitmen organisasional adalah komitmen afektif (affective commitment) $\left(\mathrm{Y}_{1}\right)$, komitmen kontinu (continuance commitment) $\left(\mathrm{Y}_{2}\right)$ dan komitmen normatif (normative commitment) $\left(\mathrm{Y}_{3}\right)$.

Bass dan Avolio (1990) menyatakan bahwa kepemimpinan transformasional adalah gaya seorang pemimpin yang membangkitkan keingan karyawannya untuk lebih berprestasi dan mengembangkan potensi yang dimiliki oleh karyawan. Menurut Bass dan Avolio (1990) adapun indikator dari kepemimpinan transformasional adalah idealized influence (karisma), $\left(\mathrm{X}_{1.1}\right)$ individual consideration (pertimbangan individual) $\left(\mathrm{X}_{1.2}\right)$, intellectual stimulation (stimulasi intelektual) $\left(\mathrm{X}_{1.3}\right)$ dan inspirational motivation (motivasi inspiratif) $\left(\mathrm{X}_{1.4}\right)$.

Teori yang dikembangkan oleh Abraham Maslow (Priansa, 2014:206) menyatakan bahwa terdapat lima tingkat atau hierarki yang menjadi sebuah kebutuhan dari setiap manusia. Teori lima tingat hierarki kebutuhan Maslow digunakan dalam penelitian ini sebagai indikator untuk mengukur variabel motivasi secara operasional yang terdiri dari kebutuhan fisiologis (physiological needs) $\left(\mathrm{X}_{2.1}\right)$, kebutuhan rasa aman (safety needs) $\left(\mathrm{X}_{2.2}\right)$, kebutuhan sosial (social needs) $\left(\mathrm{X}_{2.3}\right)$, kebutuhan akan harga diri atau pengakuan (esteem needs) $\left(\mathrm{X}_{2.4}\right)$ dan kebutuhan aktualisasi diri (self-actualization needs) $\left(\mathrm{X}_{2.5}\right)$.

Luthans (2006) dalam Syauta (2012:71) menyatakan bahwa kepuasan kerja adalah kesenangan emosional atau emosi positif yang berasal dari penilaian atau pengalaman kerja. Adapun indikator - indikator dari kepuasan kerja menurut 
Luthans (2006) dalam Syauta (2012:71) adalah pekerjaan itu sendiri (X $\left.\mathrm{X}_{3.1}\right)$, gaji $\left(\mathrm{X}_{3.2}\right)$, kesempatan promosi $\left(\mathrm{X}_{3.3}\right)$, atasan $\left(\mathrm{X}_{3.4}\right)$ dan rekan kerja $\left(\mathrm{X}_{3.5}\right)$.

Populasi dalam penelitian ini adalah seluruh karyawan yang bekerja di Wyndham Garden Hotels Kelurahan/Desa Kuta Kabupaten Badung yaitu sebanyak 119 orang karyawan. Metode sampling jenuh digunakan dalam penelitian ini dalam menentukan sampel penelitian. Sampel dalam penelitian ini adalah seluruh anggota populasi. Akan tetapi karena penelitian ini meneliti tentang kepemimpinan, maka pemimpin dari masing-masing jabatan dalam perusahaan tidak masuk menjadi sampel. Dengan demikian jumlah sampel dalam penelitian sebanyak 108 orang karyawan di Wyndham Garden Hotels Kelurahan/Desa Kuta Kabupaten Badung. Metode wawancara dan kuesioner digunakan dalam penelitian ini untuk mengumpulkan data penelitian.

Menurut Kuncoro (2009:145) data kuantitatif adalah data yang diukur dalam suatu skala numerik (angka). Data kuantitatif dalam penelitian ini adalah data jumlah karyawan dan data nilai skor jawaban responden terhadap pernyataan yang terdapat di dalam kuisioner. Menurut Kuncoro (2009:145) sebuah data yang tidak dapat diukur menggunakan skala numerik (angka) dimaksud dengan data kualitatif. Data kualitatif dalam penelitian ini adalah sejarah perusahaan, gambar struktur organisasi, maupun pernyataan dari skala likert yang dijawab oleh responden dalam bentuk sangat tidak setuju, tidak setuju, netral, setuju dan sangat setuju. Menurut Kuncoro (2009:148) data yang diperoleh melalui wawancara lapangan dengan menggunakan seluruh metode pengumpulan data murni disebut dengan data primer. Data primer dalam penelitian ini diperoleh dari wawancara 
Desak Made Lingga Suadnyani, Pengaruh Kepemimpinan Transformasional...

langsung sehingga hasil dari wawancara langsung penulis memperoleh data sejarah perusahaan, struktur organisasi dan dari kuisioner yang disebarkan kepada responden. Menurut Kuncoro (2009:148) data yang diperoleh dari sebuah lembaga pengumpul data yang dipublikasikan pada seluruh masyarakat dan dapat diakses disebut sebagai data sekunder. Namun, data sekunder dalam penelitian ini tidak digunakan.

Pengujian instrumen penelitian menggunakan uji validitas dan uji realibilitas. Pernyataan - pernyataan dalam kuesioner dikatakan valid apabila koefisien korelasi $\geq 0,3$ (Sugiyono, 2016:142). Suatu instrumen dikatakan reliabel apabila koefisien cronbach alpha $\geq 0,60$ (Sugiyono, 2016:147).

Data yang telah dikumpulkan dalam penelitian ini, selanjutnya akan dianalisis dengan cara regresi linear berganda, uji asumsi klasik yang meliputi uji normalitas, uji multikolonieritas dan uji heteroskedastisitas, uji kelayakan model (uji F) yang dilakukan guna mengetahui apakah seluruh variabel bebas yang digunakan dalam model penelitian secara bersamaan berpengaruh terhadap variabel terikat (Ghozali, 2014:98), uji hipotesis (uji t) dilakukan untuk mengetahui seberapa jauh pengaruh satu variabel bebas secara individual dalam menerangkan variasi variabel terikat (Ghozali, 2014:98). Taraf nyata atau $\alpha$ yang digunakan adalah 5\%. Apabila tingkat signifikan $\mathrm{t} \leq \alpha=0,05$ maka H0 ditolak dan $\mathrm{H} 1$ diterima. Sebaliknya apabila tingkat signifikan $\mathrm{t}<\alpha=0,05$ maka Ho diterima dan $\mathrm{H} 1$ ditolak. 


\section{HASIL DAN PEMBAHASAN}

Wyndham Garden Hotels adalah sebuah hotel bintang 3 dengan fasilitas bintang 4 terletak di Jalan Pantai Kuta 99 X Kelurahan/Desa Kuta Kabupaten Badung, Bali, Indonesia. Hotel ini berdiri sejak 2010 sebagai pengembangan dari Villa Namaste yang telah beroperasi lebih dahulu. Hotel dengan fasilitas 143 kamar ini berada di bawah manajemen PT. Global Bridge Investment Property. Sejak Januari tahun 2017 pengelolaan hotel berubah dari The Kuta Playa Hotel \& Villa's berganti nama menjadi Wyndham Garden Hotels.

Tabel 1.

Hasil Uji Validitas

\begin{tabular}{ccccc}
\hline No & Variabel & Item Pernyataan & Person Correlation & Keterangan \\
\hline 1 & Komitmen & Y1 & 0,840 & Valid \\
& Organisasional (Y) & Y2 & 0,821 & Valid \\
& & Y3 & 0,589 & Valid \\
\hline 2 & Kepemimpinan & X1.1 & 0,773 & Valid \\
& Transformasional & X1.2 & 0,823 & Valid \\
& (X1) & X1.3 & 0,681 & Valid \\
& Xotivasi (X2) & X2.4 & 0,699 & Valid \\
\hline 3 & & X2.2 & 0,571 & Valid \\
& & X2.3 & 0,628 & Valid \\
& & X2.4 & 0,377 & Valid \\
& & X2.5 & 0,759 & Valid \\
& Kepuasan Kerja & X3.1 & 0,709 & Valid \\
\hline 4 & (X3) & X3.2 & 0,523 & Valid \\
& & X3.3 & 0,684 & Valid \\
& & X3.4 & 0,721 & Valid \\
& & X3.5 & 0,682 & Valid \\
& & & 0,405 & Valid
\end{tabular}

Tabel 1 menunjukkan bahwa seluruh indikator pernyataan variabel dalam komitmen organisasional, kepemimpinan transformasional, motivasi dan kepuasan kerja memiliki person correlation $\geq 0,3$ sehingga seluruh indikator tersebut telah memenuhi syarat validitas data. 
Desak Made Lingga Suadnyani, Pengaruh Kepemimpinan Transformasional...

Pengujian reliabilitas instrumen dilakukan dengan bantuan program SPSS. Apabila nilai instrumen Alpha Cronbach $\geq 0,60$ makan disebut reliable. Adapun hasil dari uji reliabilitas dapat ditunjukkan pada tabel berikut.

Tabel 2.

Hasil Uji Reliabilitas

\begin{tabular}{clcc}
\hline No & \multicolumn{1}{c}{ Variabel } & Cronbach's Alpha & Keterangan \\
\hline 1 & Komitmen Organisasional $(\mathrm{Y})$ & 0,610 & Reliabel \\
2 & Kepemimpinan transformasional $\left(\mathrm{X}_{1}\right)$ & 0,730 & Reliabel \\
3 & Motivasi $\left(\mathrm{X}_{2}\right)$ & 0,684 & Reliabel \\
4 & Kepuasan kerja $\left(\mathrm{X}_{3}\right)$ & 0,657 & Reliabel \\
\hline \multicolumn{2}{l}{ Sumber: Data diolah, 2017}
\end{tabular}

Tabel 2 menunjukkan bahwa nilai Cronbach's Alpha dari masing-masing tabel memiliki nilai $\geq 0,60$. Berdasarkan hasil tersebut dapat diketahui bahwa seluruh variabel dalam penelitian ini adalah reliabel.

Deskripsi jawaban responden mengenai komitmen organisasional dapat diukur pada Tabel 3 yang menunjukkan bahwa rata-rata skor dari 3 pernyataan responden mengenai komitmen organisasional adalah sebesar 3,90. Nilai ini berada pada kisaran 3,31 - 4,20 yang berarti bahwa komitmen organisasional yang dimiliki karyawan Wyndham Garden Hotels Kelurahan/Desa Kuta Kabupaten Badung dalam kondisi tinggi. Tingginya komitmen organisasional karyawan terlihat dari jawaban "Salah satu alasan utama untuk melanjutkan bekerja pada organisasi ini adalah bahwa saya percaya loyalitas adalah penting" dengan skor nilai sebesar 3,94. 
Tabel 3.

Deskripsi Jawaban Responden Perihal Komitmen Organisasional

\begin{tabular}{|c|c|c|c|c|c|c|c|c|}
\hline \multirow[t]{2}{*}{ No } & \multirow[t]{2}{*}{ Pernyataan } & \multicolumn{5}{|c|}{$\begin{array}{c}\text { Proporsi Persepsi Responden } \\
(\%)\end{array}$} & \multirow[t]{2}{*}{$\begin{array}{l}\text { Rata - } \\
\text { Rata }\end{array}$} & \multirow[t]{2}{*}{ Kriteria } \\
\hline & & STS & TS & $\mathbf{N}$ & $\mathbf{S}$ & SS & & \\
\hline 1 & $\begin{array}{l}\text { Saya merasa sangat senang } \\
\text { menghabiskan sisa karir } \\
\text { saya dalam perusahaan ini } \\
\text { (Y1) }\end{array}$ & - & 4 & 31 & 45 & 28 & 3,90 & Tinggi \\
\hline 2 & $\begin{array}{lr}\text { Sangat } & \text { sulit bagi saya } \\
\text { untuk } & \text { meninggalkan } \\
\text { perusahaan ini meskipun } \\
\text { saya menginginkannya } \\
\text { (Y2) }\end{array}$ & - & 4 & 32 & 45 & 27 & 3,88 & Tinggi \\
\hline 3 & $\begin{array}{l}\text { Salah satu alasan utama } \\
\text { untuk melanjutkan bekerja } \\
\text { pada organisasi ini adalah } \\
\text { bahwa saya percaya } \\
\text { loyalitas adalah penting } \\
\text { (Y3) }\end{array}$ & - & 1 & 38 & 35 & 34 & 3,94 & Tinggi \\
\hline Rat & rata variabel komitmen 0 & inis & 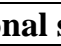 & & & 1an & 3,90 & Tinggi \\
\hline
\end{tabular}
Sumber: Data diolah, 2017

Deskripsi jawaban responden mengenai kepemimpinan transformasional dapat diukur pada Tabel 4 yang menunjukkan bahwa rata-rata skor dari 4 pernyataan responden mengenai kepemimpinan transformasional adalah sebesar 4,01. Nilai ini berada pada kisaran 3,31 - 4,20 yang berarti bahwa kepemimpinan transformasional yang dimiliki karyawan Wyndham Garden Hotels Kelurahan/Desa Kuta Kabupaten Badung dalam kondisi tinggi. Tingginya kepemimpinan transformasional karyawan terlihat dari jawaban "Atasan saya memiliki kreativitas yang tinggi dalam mencari cara untuk mencapai tujuan perusahaan" dengan skor nilai sebesar 4,06. 
Tabel 4.

Deskripsi Jawaban Responden Perihal Kepemimpinan Transformasional

\begin{tabular}{|c|c|c|c|c|c|c|c|c|}
\hline \multirow[t]{2}{*}{ No } & \multirow[t]{2}{*}{ Pernyataan } & \multicolumn{3}{|c|}{$\begin{array}{r}\text { Proporsi Persepsi } \\
(\%)\end{array}$} & \multicolumn{2}{|c|}{ Responden } & \multirow[t]{2}{*}{$\begin{array}{c}\text { Rata - } \\
\text { Rata }\end{array}$} & \multirow[t]{2}{*}{ kriteria } \\
\hline & & STS & TS & $\mathbf{N}$ & $\mathbf{S}$ & SS & & \\
\hline 1 & $\begin{array}{lr}\text { Saya mengagumi } & \text { atasan } \\
\text { saya karena dia } \\
\text { memperlakukan orang } \\
\text { lain dengan adil (X1.1) }\end{array}$ & - & 2 & 39 & 28 & 39 & 3,96 & Tinggi \\
\hline 2 & $\begin{array}{l}\text { Atasan saya adalah orang } \\
\text { yang peduli kepada } \\
\text { bawahannya }(\mathrm{X} 1.2)\end{array}$ & - & - & 31 & 45 & 32 & 4,01 & Tinggi \\
\hline 3 & $\begin{array}{l}\text { Atasan saya memiliki } \\
\text { kreativitas yang tinggi } \\
\text { dalam mencari cara } \\
\text { untuk mencapai tujuan } \\
\text { perusahaan (X1.3) }\end{array}$ & - & 1 & 23 & 52 & 32 & 4,06 & Tinggi \\
\hline 4 & $\begin{array}{l}\text { Atasan saya mampu } \\
\text { membangkitkan rasa } \\
\text { percaya diri bawahannya } \\
(\mathrm{X} 1.4)\end{array}$ & - & 1 & 27 & 47 & 33 & 4,04 & Tinggi \\
\hline
\end{tabular}
Sumber: Data diolah, 2017

Deskripsi jawaban responden mengenai motivasi dapat diukur pada Tabel 5 yang menunjukkan bahwa rata-rata skor dari 5 pernyataan responden mengenai motivasi adalah sebesar 3,91. Nilai ini berada pada kisaran 3,31 - 4,20 yang berarti bahwa motivasi yang dimiliki karyawan Wyndham Garden Hotels Kelurahan/Desa Kuta Kabupaten Badung dalam kondisi tinggi. Tingginya motivasi karyawan terlihat dari jawaban "Saya merasa memiliki banyak sahabat di tempat kerja ini” dengan skor nilai sebesar 4,00. 
Tabel 5.

Deskripsi Jawaban Responden Perihal Motivasi

\begin{tabular}{|c|c|c|c|c|c|c|c|c|}
\hline \multirow[t]{2}{*}{ No } & \multirow[t]{2}{*}{ Pernyataan } & \multicolumn{5}{|c|}{ Proporsi Persepsi Responden(\%) } & \multirow{2}{*}{$\begin{array}{l}\text { Rata- } \\
\text { Rata }\end{array}$} & \multirow[t]{2}{*}{ Kriteria } \\
\hline & & STS & TS & $\mathbf{N}$ & $\mathbf{S}$ & SS & & \\
\hline 1 & $\begin{array}{l}\text { Perusahaan } \\
\text { menyediakan sarana } \\
\text { dan prasana yang } \\
\text { mendukung semua } \\
\text { aktivitas di dalam } \\
\text { mengerjakan tugas } \\
\text { (X2.1) }\end{array}$ & - & 2 & 36 & 43 & 28 & 3,91 & tinggi \\
\hline 2 & $\begin{array}{lr}\text { Saya merasa aman } \\
\text { dalam } & \text { melaksanakan } \\
\text { pekerjaan } & \text { yang } \\
\text { diberikan } & \text { perusahaan } \\
\text { (X2.2) } & \end{array}$ & - & 3 & 22 & 66 & 17 & 3,90 & tinggi \\
\hline 3 & $\begin{array}{l}\text { Saya merasa memiliki } \\
\text { banyak sahabat di } \\
\text { tempat kerja ini }(\mathrm{X} 2.3)\end{array}$ & - & - & 25 & 58 & 25 & 4,00 & tinggi \\
\hline 4 & $\begin{array}{l}\text { Perusahaan selalu } \\
\text { memberikan hadiah } \\
\text { bagi karyawannya yang } \\
\text { berprestasi (X2.4) }\end{array}$ & - & 14 & 26 & 38 & 30 & 3,78 & tinggi \\
\hline 5 & $\begin{array}{lr}\text { Saya } & \text { senang } \\
\text { mengerjakan } & \text { tugas } \\
\text { yang menantang } & (\mathrm{X} 2.5)\end{array}$ & - & 7 & 23 & 42 & 36 & 3,99 & tinggi \\
\hline & Rata - rata variabel $n$ & tivasi & a a & selu & & & 3,91 & tinggi \\
\hline
\end{tabular}

Sumber: Data diolah, 2017

Deskripsi jawaban responden mengenai kepuasan kerja dapat diukur pada

Tabel 6 yang menunjukkan bahwa rata-rata skor dari 5 pernyataan responden mengenai kepuasan kerja adalah sebesar 3,98. Nilai ini berada pada kisaran 3,31 4,20 yang berarti bahwa kepuasan kerja yang dimiliki karyawan Wyndham Garden Hotels Kelurahan/Desa Kuta Kabupaten Badung dalam kondisi tinggi. Tingginya kepuasan kerja karyawan terlihat dari jawaban "Saya merasa senang bekerja dengan rekan kerja saya di dalam perusahaan" dengan skor nilai sebesar 4,15 . 
Tabel 6.

Deskripsi Jawaban Responden Mengenai Kepuasan Kerja

\begin{tabular}{|c|c|c|c|c|c|c|c|c|}
\hline \multirow[t]{2}{*}{ No } & \multirow[t]{2}{*}{ Pernyataan } & \multicolumn{5}{|c|}{$\begin{array}{c}\text { Proporsi Persepsi Responden } \\
(\%)\end{array}$} & \multirow[t]{2}{*}{$\begin{array}{l}\text { Rata- } \\
\text { Rata }\end{array}$} & \multirow[t]{2}{*}{ Kriteria } \\
\hline & & STS & TS & $\mathbf{N}$ & $\mathbf{S}$ & SS & & \\
\hline 1 & $\begin{array}{l}\text { Saya merasa puas dengan } \\
\text { pekerjaan yang saya } \\
\text { lakukan }(\mathrm{X} 3.1)\end{array}$ & - & - & $\begin{array}{l}3 \\
2\end{array}$ & 38 & 38 & 4,06 & Tinggi \\
\hline 2 & $\begin{array}{l}\text { Gaji yang saya terima saat } \\
\text { ini sudah sesuai dengan } \\
\text { beban kerja saya (X3.2) }\end{array}$ & - & 5 & $\begin{array}{l}3 \\
5\end{array}$ & 42 & 26 & 3,82 & Tinggi \\
\hline 3 & $\begin{array}{lr}\text { Saya } & \text { menerima } \\
\text { kesempatan } & \text { promosi } \\
\text { ketika saya melakukan } \\
\text { pekerjaan dengan baik } \\
\text { (X3.3) }\end{array}$ & - & 4 & $\begin{array}{l}3 \\
1\end{array}$ & 48 & 25 & 3,87 & Tinggi \\
\hline 4 & $\begin{array}{l}\text { Atasan saya selalu } \\
\text { memberikan pengarahan } \\
\text { yang positif terhadap } \\
\text { pekerjaan saya }(\mathrm{X} 3.4)\end{array}$ & - & 3 & 23 & 51 & 31 & 4,02 & Tinggi \\
\hline 5 & $\begin{array}{l}\text { Saya merasa senang } \\
\text { bekerja dengan rekan kerja } \\
\text { saya di dalam perusahaan } \\
(\mathrm{X} 3.5)\end{array}$ & - & - & 27 & 38 & 43 & 4,15 & Tinggi \\
\hline
\end{tabular}

\begin{tabular}{lll}
\hline Rata-rata keseluruhan variabel kepuasan kerja & 3,98 & Tinggi \\
\hline Sumber: Data diolah, 2017 &
\end{tabular}

Analisis regresi linear berganda digunakan untuk mencari koefisien regresi yang akan menentukan apakah hipotesis yang dibuat akan diterima atau ditolak. Adapun hasil dari analisis regresi linear berganda dapat dilihat pada tabel berikut.

Tabel 7.

Hasil Regresi Linear Berganda

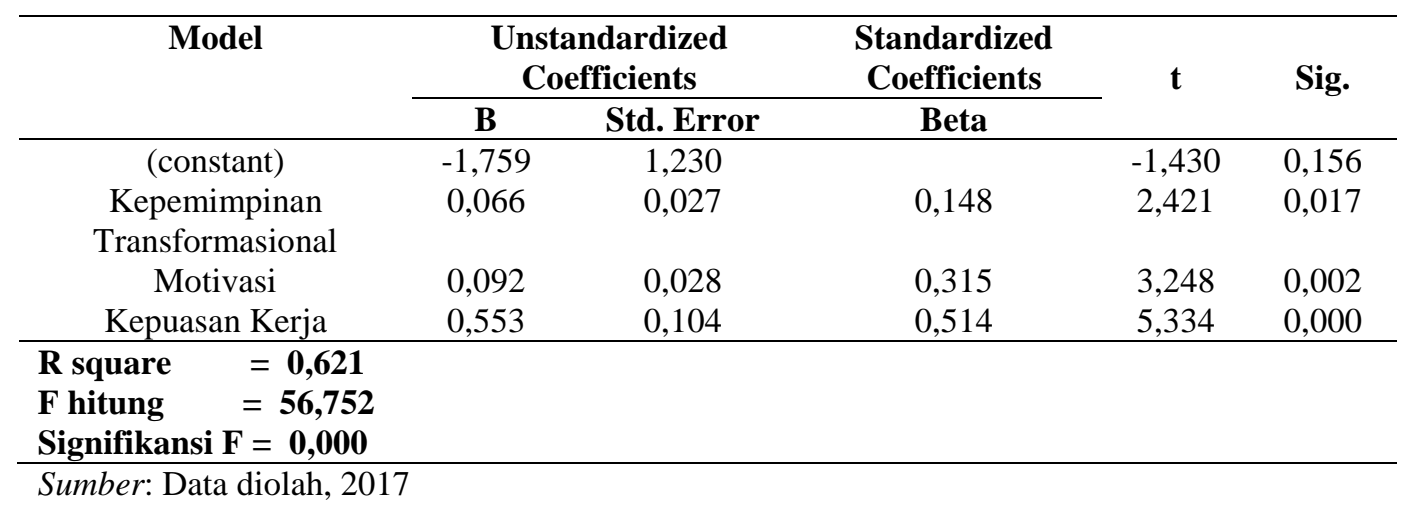


Persamaan regresi linear berganda berdasarkan Tabel 7 untuk penelitian ini adalah sebagai berikut.

$Y=-1,759+0,066 X_{1}+0,092 X_{2}+0,553 X_{3}$

Keterangan:

$\mathrm{Y}=$ Komitmen Organisasional

$\mathrm{X}_{1}=$ Kepemimpinan Transformasional

$\mathrm{X}_{2}=$ Motivasi

$\mathrm{X}_{3}=$ Kepuasan Kerja

Berdasarkan persamaan tersebut, maka seluruh variabel yang digunakan yaitu kepemimpinan transformasional, motivasi dan kepuasan kerja memiliki pengarh terhadap komitmen organisasional karyawan di Wyndham Garden Hotels Kelurahan/Desa Kuta Kabupaten Badung.

1. $\beta_{1}=0,066$ berarti pengaruh kepemimpinan transformasional $\left(\mathrm{X}_{1}\right)$ mengakibatkan peningkatan komitmen organisasional (Y) karyawan, dengan asumsi variabel bebas yang lainnya dianggap konstan.

2. $\beta_{2}=0,092$ berarti pengaruh motivasi $\left(\mathrm{X}_{2}\right)$ mengakibatkan peningkatan komitmen organisasional (Y) karyawan, dengan asumsi variabel bebas yang lainnya dianggap konstan. 
Desak Made Lingga Suadnyani, Pengaruh Kepemimpinan Transformasional...

3. $\beta_{3}=0,553$ berarti pengaruh kepuasan kerja $\left(\mathrm{X}_{3}\right)$ mengakibatkan peningkatan komitmen organisasional (Y) karyawan, dengan asumsi variabel bebas yang lainnya dianggap konstan.

Berdasarkan Tabel 4.11 nilai $\mathrm{R}$ square sebesar 0,621 mempunyai arti bahwa 62,1 persen komitmen organisasional karyawan di Wyndham Garden Hotels Kelurahan/Desa Kuta Kabupaten Badung dipengaruhi oleh kepemimpinan transformasional, motivasi dan kepuasan kerja yang diterapkan di perusahaan. Sedangkan sisanya sebesar 37,9 persen dipengaruhi oleh faktor-faktor lain yang tidak dijelaskan dalam penelitian ini.

Tabel 8.

Uji Normalitas

\begin{tabular}{cc}
\hline & Unstandardized residual \\
\hline $\mathrm{N}$ & 108 \\
Kolmogorov-smirov Z & 0,618 \\
Asymp. sig (2-tailed) & 0,840 \\
\hline Sumber: Data diolah, 2017 &
\end{tabular}

Sumber: Data diolah, 2017

Berdasarkan Tabel 8 menunjukkan bahwa nilai Kolmogorov-Smirov Z sebesar 0,618, dengan nilai Asymp. Sig (2-tailed) sebesar 0,840. Nilai asymp. sig (2-tailed) 0,840 yang lebih besar daripada nilai alpha sebesar 0,05 mengidentifikasi bahwa model persamaan regresi yang digunakan berdistribusi normal.

Tabel 9.

Hasil Uji Multikolinearitas

\begin{tabular}{lcc}
\hline \multicolumn{1}{c}{ Variabel } & Tolerance & VIF \\
\hline Kepemimpinan transformasional $\left(\mathrm{X}_{1}\right)$ & 0,979 & 1,021 \\
Motivasi $\left(\mathrm{X}_{2}\right)$ & 0,389 & 2,573 \\
Kepuasan Kerja $\left(\mathrm{X}_{3}\right)$ & 0,393 & 2,543 \\
\hline Sumber: Data diolah 2017 & &
\end{tabular}


Berdasarkan Tabel 9 dapat dilihat bahwa nilai tolerance dan VIF dari variabel kepemimpinan transformasional, motivasi dan kepuasan kerja. Nilai tersebut menunjukkan bahwa nilai tolerance untuk setiap variabel lebih besar dari 0,10 (10\%) dan nilai VIF lebih kecil dari 10 yang berarti model persamaan regresi bebas dari multikolinearitas.

Tabel 10.

Uji Heteroskedastisitas

\begin{tabular}{ccccccc}
\hline Model & \multicolumn{2}{c}{$\begin{array}{c}\text { Unstandardized } \\
\text { coefficients }\end{array}$} & $\begin{array}{c}\text { Standardized } \\
\text { coefficients }\end{array}$ & t & Sig. \\
\cline { 2 - 5 } & $\mathbf{B}$ & Std. Error & Beta & & \\
\hline (constant) & 1,919 & 1,139 & & & 1,684 & 0,095 \\
Kepemimpinan & $-0,029$ & 0,049 & $-0,062$ & & $-0,605$ & 0,546 \\
Transformasional & & & & & \\
Motivasi & $-0,031$ & 0,049 & $-0,071$ & & $-0,642$ & 0,523 \\
Kepuasan Kerja & 0,029 & 0,049 & 0,063 & & 0,584 & 0,561 \\
\hline
\end{tabular}

Sumber: Data diolah, 2017

Berdasarkan Tabel 10 dapat dilihat bahwa nilai Sig. dari variabel kepemimpinan transformasional sebesar 0,546, motivasi sebesar 0,523 dan kepuasan kerja sebesar 0,561 . Nilai tersebut lebih besar dari 0,05 yang berarti tidak terdapat pengaruh antara variabel bebas terhadap absolute residual. Dengan demikian, model yang dibuat tidak mengandung gejala heteroskedastisitas.

Tabel 11.

Hasil Uji F

\begin{tabular}{cccccc}
\hline Model & Sum of squares & DF & Mean square & F & Sig. \\
\hline Regression & 285,357 & 3 & 95,119 & 56,752 & 0,000 \\
Residual & 174,310 & 104 & 1,676 & & \\
\hline total & $\mathbf{4 5 9 , 6 6 7}$ & $\mathbf{1 0 7}$ & & & \\
\hline Sumber: Data diolah, 2017 & & &
\end{tabular}

Berdasarkan Tabel 11 menunjukkan nilai signifikansi sebesar 0,000 yang lebih kecil dari nilai $\alpha=0,05$ maka model regresi linear berganda layak digunakan sebagai alat analisis untuk menguji pengaruh variabel bebas terhadap variabel terikat. 
Tabel 12.

Hasil Uji t

\begin{tabular}{ccc}
\hline No & Variabel & Sig.t \\
\hline 1 & Kepemimpinan Transformasional & 0,017 \\
2 & Motivasi & 0,002 \\
3 & Kepuasan Kerja & 0,000 \\
\hline
\end{tabular}

Sumber: Data diolah, 2017

Kriteria pengujian untuk menjelaskan interpretasi pengaruh antar masingmasing variabel adalah sebagai berikut.

Jika Sig.t $<0,05$ maka $\mathrm{H}_{0}$ ditolak dan $\mathrm{H}_{1}$ diterima.

Jika Sig.t > 0,05 maka $\mathrm{H}_{0}$ diterima dan $\mathrm{H}_{1}$ ditolak.

Berdasarkan hasil uji t dan nilai signifikansi pada variabel kepemimpinan transformasional $\left(\mathrm{X}_{1}\right)$ menunjukkan nilai sig. lebih kecil dari 0,05 maka dapat disimpulkan bahwa, kepemimpinan transformasional $\left(\mathrm{X}_{1}\right)$ berpengaruh positif dan signifikan terhadap komitmen organisasional (Y). Hal ini berarti semakin baik penerapan kepemimpinan transformasional maka semakin tinggi komitmen organisasional karyawan. Hasil penelitian ini sesuai dengan penelitian yang dilakukan oleh Njoroge et al. (2015) menyatakan bahwa kepemimpinan transformasional memiliki pengaruh yang signifikan terhadap komitmen organisasional. Supit (2016) menyatakan bahwa kepemimpinan transformasional berpengaruh signifikan terhadap komitmen organisasional. Bushra et al. (2011) menyatakan bahwa kepemimpinan transformasional memiliki pengaruh yang positif terhadap kepuasan kerja dan komitmen organisasional. Jain dan Taranjeet (2016) juga menemukan bahwa kepemimpinan transformasional berpengaruh positif terhadap komitmen organisasional. 
Berdasarkan hasil uji t dan nilai signifikansi pada variabel motivasi $\left(\mathrm{X}_{2}\right)$ menunjukkan nilai sig. lebih kecil dari 0,05 maka dapat disimpulkan bahwa, motivasi $\left(\mathrm{X}_{2}\right)$ berpengaruh positif dan signifikan terhadap komitmen organisasional (Y). Hal ini berarti semakin baik motivasi yang diberikan kepada karyawan maka semakin tinggi komitmen organisasional karyawan. Hasil penelitian ini sesuai dengan penelitian yang dilakukan oleh Awolusi (2013) menyatakan bahwa motivasi berpengaruh positif terhadap komitmen karyawan. Wardhani dkk. (2015) menyatakan bahwa motivasi berpengaruh secara signifikan terhadap komitmen organisasional. Sharma et al. (2016) menyatakan bahwa motivasi berpengaruh signifikan terhadap komitmen karyawan. Hasil penelitian dari Salleh et al. (2016) menyatakan bahwa ada pengaruh positif antara motivasi kerja dan komitmen organisasional. Putri dkk. (2015) menyatakan bahwa motivasi kerja berpengaruh signifikan terhadap komitmen organisasional.

Berdasarkan hasil uji t dan nilai signifikansi pada variabel kepuasan kerja $\left(\mathrm{X}_{3}\right)$ menunjukkan nilai sig. lebih kecil dari 0,05 maka dapat disimpulkan bahwa, kepuasan kerja $\left(\mathrm{X}_{3}\right)$ berpengaruh positif dan signifikan terhadap komitmen organisasional (Y). Hal ini berarti semakin tinggi kepuasan kerja yang dirasakan oleh karyawan maka semakin tinggi komitmen organisasional karyawan. Hasil penelitian ini sesuai dengan penelitian yang dilakukan oleh Shah (2014) menyatakan bahwa kepuasan kerja berpengaruh positif terhadap komitmen organisasional. Imam et al. (2014) menyatakan bahwa kepuasan kerja berpengaruh positif dan signifikan terhadap komitmen organisasional. Wardhani dkk. (2015) menyatakan bahwa kepuasan kerja berpengaruh signifikan terhadap 
Desak Made Lingga Suadnyani, Pengaruh Kepemimpinan Transformasional...

komitmen organisasional. Tentama dan Pranungsari (2016) menyatakan bahwa kepuasan kerja memiliki pengaruh positif terhadap komitmen organisasional.

\section{SIMPULAN DAN SARAN}

Berdasarkan hasil analisis penelitian dan hasil pembahasan dari pada babbab sebelumnya, maka simpulkan dari penelitian ini adalah kepemimpinan transformasional berpengaruh positif dan signifikan terhadap komitmen organisasional di Wyndham Garden Hotels Kelurahan/Desa Kuta Kabupaten Badung. Hal ini sesuai dengan hipotesis pertama (H1) yang menyatakan bahwa kepemimpinan transformasional berpengaruh positif dan signifikan terhadap komitmen organisasional. Motivasi berpengaruh positif dan signifikan terhadap komitmen organisasional di Wyndham Garden Hotels Kelurahan/Desa Kuta Kabupaten Badung. Hal ini sesuai dengan hipotesis kedua (H2) yang menyatakan bahwa motivasi berpengaruh positif dan signifikan terhadap komitmen organisasional. Kepuasan kerja berpengaruh positif dan signifikan terhadap komitmen organisasional di Wyndham Garden Hotels Kelurahan/Desa Kuta Kabupaten Badung. Hal ini sesuai dengan hipotesis ketiga (H3) yang menyatakan bahwa kepuasan kerja berpengaruh positif dan signifikan terhadap komitmen organisasional.

Berdasarkan hasil analisis penelitian, pembahasan dan simpulan terdapat beberapa saran yang dapat diberikan adalah sebagai berikut. Pertama, seorang pemimpin diharapkan selalu bersikap adil didalam perusahaan dengan cara memberikan kesempatan yang sama bagi karyawan untuk ikut dalam pengambilan 
keputusan. Dengan demikian, karyawan akan merasa keberadaannya akan lebih dihargai dan hal tersebut dapat meningkatkan komitmen organisasional karyawan terhadap perusahaan. Kedua, manajemen diharapkan mampu meningkatkan motivasi kerja karyawan dengan cara rutin memberikan penghargaan bagi karyawan yang berprestasi. Menjaga dan memperhatikan motivasi yang diberikan kepada karyawannya akan meningkatkan komitmen organisasional karyawan terhadap perusahaan. Ketiga, manajemen diharapkan mampu meningkatkan kepuasan kerja karyawan dengan cara memberikan gaji sesuai dengan beban kerja karyawan. Jika gaji yang diberikan perusahaan sudah sesuai dengan beban kerja karyawan, maka hal tersebut akan meningkat komitmen organisasional karyawan terhadap perusahaan.

\section{REFERENSI}

Abu-Tineh, A. M., Khasawneh, S. A., Al-Omari, A.A. 2009. Kouzes and Posner's Transformational Leadership Model In Practice: The Case Of Jordanian Schools. Leadership \& Organization Development Journal, 7 (3), 648-660.

Adinata, Ujang Wawan Sam. 2015. Pengaruh kepemimpinan transformasional, motivasi, dan budaya organisasi terhadap kinerja karyawan KJKS BMT Tamziz Bandung. Jurnal Ekonomi, Bisnis \& Entrepreneurship, 9 (2), 136157.

Agusthina, Risambessy, Bambang Swasto, Armanu Thoyib, Endang Siti Astuti. 2012. The Influence of Transformational Leadership Style, Motivation, Burnout towards Job Satisfaction and Employee Performance. Journal Basic.Appl.Sci.Research, 2 (9), 8833-8842.

Alam, Titah Mustika., Taher Alsabji dan Kusdi Raharjo. 2013. Pengaruh Gaya Kepemimpinan Transformasional dan Budaya Organisasi Terhadap Kepuasan Kerja Pegawai (Studi Pada Pegawai Kantor Pusat PT Pelabuhan Indonesia III (Persero) Surabaya. Jurnal Administrasi Bisnis, 2 (2), 1-6. 
Desak Made Lingga Suadnyani, Pengaruh Kepemimpinan Transformasional...

Altinoz, Mehmet., Demet Cakiroglu., and Serdar Cop. 2012. The Effect of Job Satisfaction of the Talented Employees on Organizational Commitment: A Field Research. Procedia - Social and Behavioral Sciences, 58 (2012), 322 -330 .

Awolusi, Olawumi Dele. 2013. Effects Of Motivation On Employees Job Commitment In The Nigerian Banking Industry: An Empirical Analysis. International Journal of Business and Innovation Research, 1 (3), 1-17.

Aydogdu, Sinem dan Baris Asikgil. 2011. An Empirical Study of Relationship Among Job Satisfaction, Organizational Commitment and Turnover Intention. International Review of Management and Marketing, 1 (3), 43-53.

Bass dan Avolio. 1990. Developing Transformational Leadership: 1992 and Beyond. Journal of European Industrial Training, 14 (5), 21-27.

Bushra, Fatima., Ahmad Usman., and Asvir Naveed. 2011. Effect of Transformational Leadership on Employees' Job Satisfaction and Organizational Commitment in Banking Sector of Lahore (Pakistan). International Journal of Business and Social Science, 2 (18), 261-267.

Ek Kiruja dan Elegwa Mukuru. 2013. Effect Of Motivation On Employee Performance In Public Middle Level Technical Training Institutions In Kenya. International Journal of Advances in Management and Economics, 2(4), 73-82.

Ghozali, Imam. 2014. Aplikasi Analisis Multivariate dengan Program IBM SPSS 21. Edisi ke-7. Semarang: Universitas Diponegoro.

Han, Sia Tjuan, Agustinus Nugroho, Endo W., Kartika dan Thomas, S. 2012. Komitmen Afektif Dalam Organisasi yang dipengaruhi Perceived Organizational Support dan Kepuasan kerja. Jurnal Manajemen dan Kewirausahaan, 14 (2), 109-117.

Hasibuan, Malayu S.P. 2012. Manajemen Sumber Daya Manusia. Jakarta: PT. Bumi Aksara.

Hasibuan, Malayu S.P. 2012. Organisasi dan Motivasi. Jakarta: PT. Bumi Aksara.

Hughes, R.L., Ginnett, R.C., dan Curphy, G.J. 2012. Leadership: Memperkaya Pelajaran dari Pengalaman. Edisi Ke-7. Jakarta: Salemba Humanika.

Imam, Abeer., Raza, Aiman and Ahmed, Mansoor. 2014. Impact Of Job Satisfaction On Organizational Commitment In Bank Sector Employees Of Pakistan. Sci.Int(Lahore), 26 (1), 419-423. 
Jain, Priyanka., and Duggal, Dr. Taranjeet. 2016. The Influence of Transformational Leadership and Emotional Intelligence on Organizational Commitment. Journal of Commerce \& Management Thought, 7 (3), 586-598.

Jain, Priyanka., and Duggal, Taranjeet. 2015. The Role Of Transformational Leadership in Organizational Commitment. International Journal of Business Quantitative Economics and Applied Management Research, 2 (5), $1-11$.

Kresnandito, Andika Putra dan Fajrianthi. 2012. Pengaruh Persepsi Kepemimpinan Transformasional Terhadap Perilaku Inovatif Penyiar Radio. Jurnal Psikologi Industri dan Organisasi, 1(2), 96-103.

Kumar, R., Ramendran, C., and Yacob, P. 2012. A Study on Turnover Intention in Fast Food Industry: Employees' Fit to the Organizational Culture and the Important of their Commitment. International Journal of Academic Research in Business Social Sciences, 2 (5), 9-42.

Kuncoro, Mudrajad. 2009. Metode Riset untuk Bisnis \& Ekonomi Edisi 3. Jakarta: Penerbit Erlangga.

Manullang, M., dan Marihot Manullang. 2008. Manajemen Personalia. Yogyakarta: Gadjah Mada University Press.

Meyer dan Allen. 1991. A Three Component Conceptualization Of Organizational Commitment. Human Resource Management Review, 1 (1), 61-89.

Mohamed, Sheik., Anisa. 2012. Relationship Between Organizational Commitment and Organizational Citizenship Behavior. The IUP Journal of Organizational Behavior. 9 (3), 122-143.

Njoroge, D, Gachunga, H, dan Kihoro, J. 2015. Transformasional Leadership Style and Organizational Commitment: The Moderating Effect Of Employee Participation. The Strategic Journal of Business \& Change Management, 2 (6), 94-107.

Northouse, Peter. 2013. Kepemimpinan. Edisi Keenam. Jakarta: PT. Indeks.

Priansa, Donni Juni. 2014. Perencanaan dan Pengembangan SDM. Bandung: Alfabeta.

Purnama, Nurul Qomarianing, Sunuharyo, Bambang Swasto dan Prasetya, Arik. 2016. Pengaruh Motivasi Kerja Terhadap Komitmen Organisasional dan Kinerja Karyawan (Studi Pada Karyawan Bank BRI cabang Kawi Malang). Jurnal Administrasi Bisnis (JAB), 40 (2), 39-47. 
Desak Made Lingga Suadnyani, Pengaruh Kepemimpinan Transformasional...

Putri, Nurdiana Eka, Abdul Hakim, dan M. Makmur. 2015. Pengaruh Motivasi Kerja dan Kemampuan Kerja Terhadap Komitmen Organisasional dan Kinerja Pegawai. JISIP: Jurnal Ilmu Sosial dan Ilmu Politik, 4 (1), 31-42.

Rehman, Khalid., Zia Ur Rehman., Naveed Saif., Abdul Sattar Khan., Allah Nawaz., and Shafiq Ur Rehman. 2013. Impacts of Job Satisfaction on Organizational Commitment: A Theoretical Model for Academicians in HEI of Developing Countries like Pakistan. International Journal of Academic Research in Accounting, Finance and Management Sciences, 3(1), 80-89.

Robbins, Stephen P. 1996. Perilaku Organisasi: Konsep, Kontroversi, Aplikasi. Jakarta: Prenhalindo.

Robbins, Stephen P. 2015. Perilaku Organisasi. Jakarta: Salemba Empat.

Robbins, Stephen., and Judge, Timothy.A. 2008. Perilaku Organisasi (Organizational Behavior). Jakarta: Salemba Empat.

Saeed, Imran. 2015 Effect of Transformational Leadership on Employee Organizational Commitment: Moderating Role of Emotional Intelligence. British Journal of Economics, Management \& Trade, 6 (4), 276-283.

Salleh, R., Mishaliny, N.S., and Haryani, H. 2012. Job Satisfaction, Organizational Commitment and Turnover Intention: A Case Study on Employees of A Retail Company in Malaysia. World Academy of Sciemce, Engineering and Technology, 72 (1), 316-323.

Salleh,Suzila Mat., Ahmad Suffian Mohd Zahari., Nur Shafini Mohd Said., and Siti Rapidah Omar Ali. 2016. The Influence of Work Motivation on Organizational Commitment in the Workplace. Journal of Applied Environmental and Biological Sciences, 6 (5S), 139-143.

Shah, Faisal Tehseen., Fahmeed Idrees., Abeer Imam., Tahir Aziz Khan., and Aiza Mariyam. 2014. Impact of Job Satisfaction on Organizational Commitment in IT Sector Employees of Pakistan. Journal of Applied Environmental and Biological Sciences, 4 (8), 190-197.

Shaheen, Abnas dan Farooqi, Yasir Aftab. 2014. Relationship among Employee Motivation, Employee Commitment, Job Involvement, Employee Engagement: A Case Study of University of Gujrat, Pakistan. International Journal Of Multidisicplinary Sciences and Engineering, 5 (9), 12-18.

Sharma, Richa, Sharma, Pooja, dan Pandey, V.K. 2016. Motivation and Quality Of Work Life (QWL) Programmes As Predictors of Employee Commitment: A Study Of Service Organisation In Gwalior Region. Journal of Organisation and Human Behaviour, 5 (1), 37-41. 
Simanjuntak, Friskha Dora dan Calam, Ahmad. 2012. Pengaruh Kepemimpinan Transformasional dan Motivasi Kerja Terhadap Kinerja Karyawan PT. PLN (Persero) Cabang Binjai Wilayah Sumatera Utara. Jurnal Saintikom, 11 (2), 80-86.

Sopiah. 2008. Perilaku Organisasional. Yogyakarta: CV. Andi Offset.

Sugiyono. 2012. Metode Penelitian Bisnis. Bandung: Alfabeta.

Sugiyono. 2016. Metode Penelitian Administratif Dilengkapi Dengan Metode $R \& D$. Bandung: Alfabeta.

Sumanto dan Herminingsih, Anik. 2016. Pengaruh Budaya Organisasi dan Motivasi Kerja Terhadap Komitmen Organisasional Pada PT. Bank Central Asi, Tbk Kantor Cabang Utama Tangerang. Jurnal Ilmiah Manajemen dan Bisnis, 2 (1), 96-110.

Supit, Isa Yohannes Israel. 2016. Pengaruh Gaya Kepemimpinan Transformasional Terhadap Komitmen Organisasional dan Organizational Citizenship Behavior yang Dimediasi Oleh Kepuasan Kerja. Jurnal Riset Bisnis dan Manajemen, 4 (3), 351-368.

Surbakti. 2013. Analisis Pengaruh Kepemimpinan Transformasional dan Motivasi terhadap Kinerja Pegawai: Studi pada PT. Kereta Api Indonesia Daop IV Semarang. Journal Fakultas Ekonomi Universitas Diponegoro Semarang, 1 (1), 55-67.

Sutrisno, H. Edy. 2014. Manajemen Sumber Daya Manusia. Jakarta: Kencana Prenada Media Group.

Suyana Utama, Made. 2007. Aplikasi Analisis Kuntitatif. Denpasar: Sastra Utama.

Syauta, Jack Henry., Eka Afnan Troena., Margono Setiawan., and Solimun. 2012.The Influence of Organizational Culture, Organizational Commitment to Job Satisfaction and Employee Performance (Study at Municipal Waterworks of Jayapura, Papua Indonesia). International Journal of Business and Management Invention, 11 (1), 69-76.

Taurisa, Chaterina Melina., Ratnawati, Intan. 2012. Analisis Pengaruh Budaya Organisasi dan Kepuasan Kerja Terhadap Komitmen Organisasional Dalam Meningkatkan Kinerja Karyawan (Studi Pada PT. Sido Muncul Kaligawe Semarang). Jurnal Bisnis dan Ekonomi (JBE), 19(2), 170-187.

Teguh, Ambar dan Sulistiyani Rosidah. 2009. Manajemen Sumber Daya Manusia Konsep, Teori dan Pengembangan Dalam Konteks Organisasi Publik. Edisi 2. Yogyakarta: Graha Ilmu. 
Desak Made Lingga Suadnyani, Pengaruh Kepemimpinan Transformasional...

Tentama dan Pranungsari. 2016. The Roles of Teachers' Work Motivation and Teachers' Job Satisfaction in the Organizational Commitment in Extraordinary Schools. International Journal of Evaluation and Research in Education (IJERE), 5 (1), 39-45.

Terry, George R dan Leslie W Rue. 2009. Dasar - Dasar Manajemen. Cetakan kesebelas. Jakarta: PT. Bumi Aksara.

Wardhani, Winda Kusuma, Heru Susilo dan Mohammad Iqbal. 2015. Pengaruh Motivasi Kerja Terhadap Komitmen Organisasional dengan kepuasan kerja sebagai variabel intervening. Jurnal Administrasi Bisnis (JAB), 2 (1), 1-10.

Widyaningrum, Mahmudah Enny. 2011. Influence Of Motivation and Culture On Organizational Commitmen and Performance Of Employee Of Medical Service. Academic Research International, 1 (3), 228-235.

Wirawan, I Gusti Putu Nata. 2002. Cara Mudah Memahami Statistik 2 (Statistik Inferensial) untuk ekonomi dan bisnis. Denpasar : edisi kedua. Keraras Emas.

Zainal, Veithzal Rivai, Muliaman Darmansyah Hadad dan H. Mansyur Ramly. 2014. Kepemimpinan dan Perilaku Organisasi. Edisi Keempat. Jakarta: PT. Raja Grafindo Persada. 